\title{
ОСОБЕННОСТИ УДОВЛЕТВОРЕННОСТИ ЖИЗНЬЮ И УЧЕБНОЙ МОТИВАЦИИ СТУДЕНТОВ, ЗАНИМАЮЩИХСЯ ТВОРЧЕСТВОМ
}

Ахрямкина Т.А. (Самарский филиал государственного автономного образовательного учреждения высшего образования города Москвы, Самара, Россия) tamara-rus@mail.ru

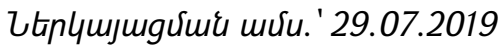

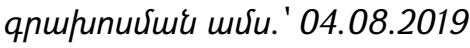

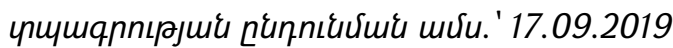

В данной статье рассматриваются проблемы профессионального и личностного самоопределения молодых людей. Проанализированы характерные особенности учебной мотивации и удовлетворенности жизнью студентов педагогического вуза, занимающихся в творческом коллективе. Обозначены подходы к понятию "жизненная удовлетворенность" психологов различных направлений. На основе проведенного исследования определяется роль занятий творчеством студентами в их дальнейшем профессиональном становлении.

Ключевые слова: самоопределение, учебная мотивачия, жизненная удовлетворенность, творчество.

Целью системы высшего образования на современном этапе является формирование профессионала, исходя из потребностей рынка труда. Однако, стоит отметить, что система образования готовит не только специалиста, она также формирует личность молодого человека. Профессиональные знания и навыки неотделимы от личности, они не развиваются отдельно от личностных качеств [5].

Одним из главных условий совершенствования профессиональной подготовки является учет социально-психологических детерминант, в частности ценностномотивационных, которые во многом определяют процесс становления индивидуальности будущего специалиста.

Современные студенты включены в большинство процессов экономических и социальных изменений, что происходят в обществе. На наш взгляд, мотивы, отношения, установки и другие проявления личности обучающихся необходимо рассматривать через призму присущего им образа жизни, которая не ограничивается только процессом обучения. Дополнительные занятия творческой деятельностью могут иметь огромное влияние на личность студента - на его мотивационные установки, общую удовлетворенность жизнью и, безусловно, на процесс как личностного, так и профессионального самоопределения.

По мнению И.А.Зимней "студенчество включает людей, целенаправленно, систематически овладевающих знаниями и профессиональными умениями, 
отличающихся наиболее высоким образовательным уровнем, наиболее активным потреблением культуры и высоким уровнем познавательной мотивации" [4, с. 65]. Многоаспектность и сложность проблемы мотивации обусловливает множественность подходов к пониманию ее сути, природы, структуры, а также к методикам её изучения. Важным в изучении мотивации является представление о ней как о сложной системе, в которую включены элементы, находящиеся в строгой иерархии. Здесь следует отметить работы Л.И.Божович, Б.И.Додонова, Е.И.Савонько. Для нас значимым предстаёт положение исследователей о том, что структура мотивационной сореры является не статичной, а развивающейся, эволюционирующей в процессе жизнедеятельности субъекта.

С этой точки зрения, важным для исследования структуры мотивации является выделение Б.И.Додоновым ее структурных элементов: удовольствия от самой деятельности, значимости для личности непосредственного ее результата, «мотивирующей» силы вознаграждения за деятельность, принуждающего давления на личность [3, с. 56].

Учебная мотивация определяется как вид мотивации, включенный в деятельность, в данном случае деятельность учения, учебную деятельность. Она дает возможность индивиду определить как направление, так и способы реализации различных форм учебной деятельности.

Мотивация учения складывается из ряда постоянно изменяющихся и вступающих в новые отношения друг с другом побуждений (потребности и смысл учения для студента, его мотивы, цели, эмоции, интересы). Поэтому "становление мотивации есть не простое возрастание положительного или усугубление отрицательного отношения к учению, а стоящее за ним усложнение структуры мотивационной сореры, входящих в нее побуждений, появление новых, более зрелых, иногда противоречивых отношений между ними" [2, с. 166]. Преобладание тех или иных мотивов во многом определяет удовлетворенность или неудовлетворенность жизнью. С точки зрения психологии, удовлетворенность жизнью представляет собой "...сложное, динамичное социально-психологическое образование, основанное на интеграции когнитивных и эмоционально-волевых процессов, характеризующееся субъективным эмоционально-оценочным отношением... и обладающее побудительной силой, способствующей действию, поиску, управлению внутренними и внешними объектами" [1, с.34]. Трудностью в исследовании удовлетворенности жизнью является, прежде всего, то, что подчеркивается ее субъективный характер.

Р. М. Шамионов рассматривает общую удовлетворенность жизнью как "сложное, постоянно изменяющееся социально-психологическое образование, основанное на единении познавательных и эмоционально-волевых процессов, характеризующееся субъективным эмоционально-оценочным отношением и обладающее побудительной силой, сподвигающей к действию, поиску, управлению внутренними и внешними объектами" [6, с. 122]. 
Основываясь на этих теоретических положениях, нами было проведено исследование, целью которого было - выделить особенности учебной мотивации и удовлетворенности жизнью студентов, занимающихся творчеством во время обучения в вузе.

Гипотеза исследования - основным мотивом обучения в вузе студентов, занимающихся творчеством, будет мотив получения диплома, а не овладение профессией. Кроме того индекс и характеристики удовлетворенности жизнью таких студентов будут отличаться от этих характеристик других студентов.

Исследование проводилось на базе Самарского филиала Государственного автономного образовательного учреждения высшего образования города Москвы "Московский городской педагогический университет". Выборку составили 40 студентов 2-4 курсов, возраст от 19 лет до 21 года, из них 20 человек постоянно занимающиеся в танцевальном коллективе современного танца более 1 года.

В качестве организационного метода был выбран сравнительный, так как мы рассматривали две группы студентов: студенты, обучающиеся в педагогическом университете и занимающиеся дополнительно в танцевальном коллективе - 1 группа и студенты, не занимающиеся дополнительно творчеством - 2 группа. Диагностическими методиками явились: методика изучения мотивации обучения в вузе Т.И. Ильиной и тест индекса жизненной удовлетворенности (ИЖУ) (адаптация Н. В. Паниной). Для математической обработки данных нами использовалось угловое преобразование Фишера (критерий Фишера).

В ходе психодиагностического исследования по методике Т.И. Ильиной были получены следующие результаты:

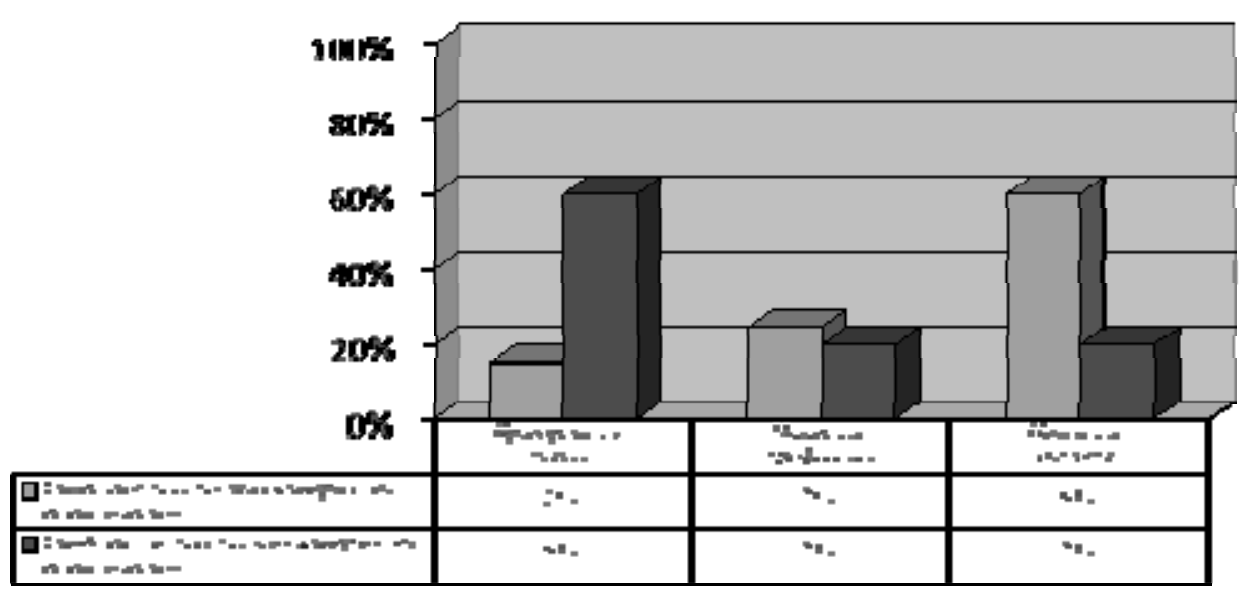

Рис. 1. Мотивы обучения в ВУЗе

Как видно из рисунка, у обеих групп студентов мотив, направленный на овладение профессией не является ведущим, что, скорее всего говорит о 
недостаточно осознанном выборе профессионального учебного заведения студентами, принявшими участие в исследовании.

В группе студентов, занимающихся в танцевальном коллективе преобладает мотив, направленный на получение диплома - 60 \%, против 20\% студентов, не занимающихся дополнительно творчеством. Также и мотив, направленный на приобретение знаний не является центральным при обучении студентов 1 группы всего $15 \%$ по сравнению с 60\% студентов 2 группы. Данные результаты являются достоверными и подтверждены коэффициентами углового преобразования Фишера. Для определения особенностей удовлетворенности жизнью студентов, занимающихся дополнительно творчеством, нами был использован тест «Индекс жизненной удовлетворенности (ИЖУ)», адаптация Н.В. Паниной. В ходе психодиагностического исследования по тесту "Индекс жизненной удовлетворенности (ИЖУ)", адаптация Н.В. Паниной были получены следующие результаты:

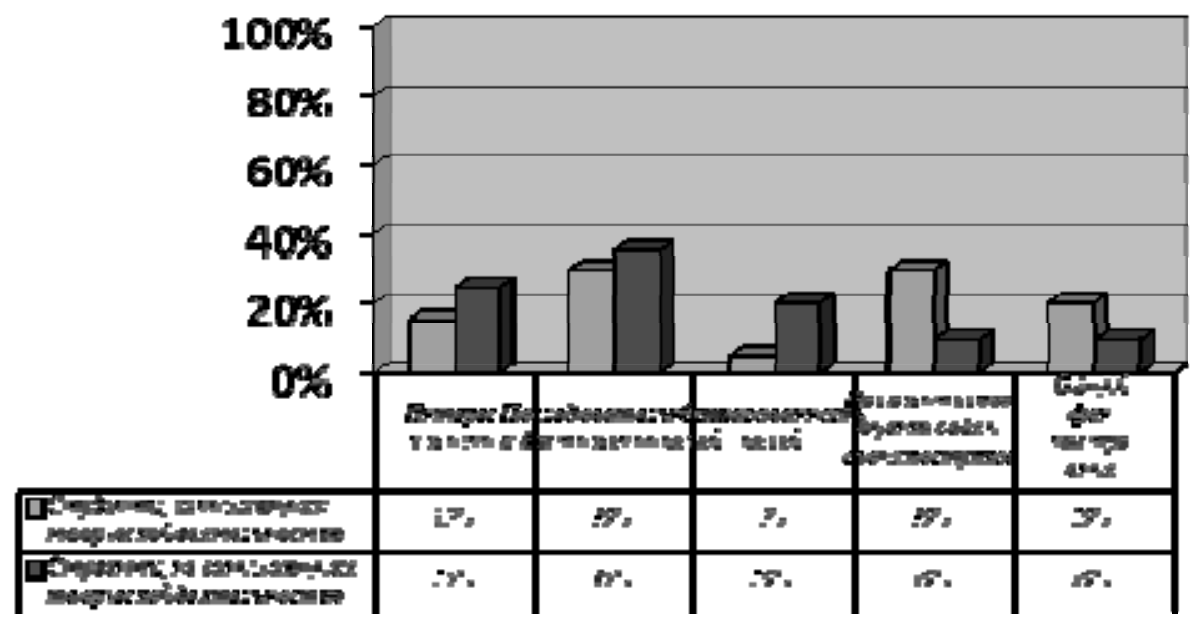

Рис. 2 Шкалы жизненной удовлетворенности.

При обработке результатов с помощью критерия углового преобразования Фишера мы получили следующие достоверные различия:

- $\quad$ по шкале "положительная оценка себя и собственных поступков" - $\boldsymbol{\varphi}_{\text {эмп }}=3.642$. Следовательно, студенты занимающиеся танцами имеют более высокую самооценку. Основания для этого дают успешные выступления и внимание со стороны других студентов.

- по шкале "согласованность между поставленными и достигнутыми целями" $\boldsymbol{\varphi}_{\text {эмп }}^{*} 3.366$ Студенты, не занимающиеся танцами характеризуются большей согласованностью целей. Для них более характерна уверенность в возможности достижения своих целей. Если принять во внимание, что ведущим мотивом этих студентов является мотив получения знаний, то они более сконцентрированы на достижении этой цели, чем студенты, занимающиеся в танцевальном коллективе, доминирующим мотивом которых является получение диплома. 
- по шкале "общий фон настроения" - $\varphi^{*}$ эмп $=3.642$. Полученное эмпирическое значение ц* находится в зоне неопределенности, но мы можем увидеть тенденцию к тому, что общий фон настроения у студентов, занимающихся творческой деятельностью выше. Им в большей степени присущи оптимизм, радость жизни, что, несомненно, дают занятия творчеством.

- Анализ общего показателя индекса жизненной удовлетворенности студентов, занимающихся в танцевальном коллективе показал следующие достоверные различия:

для 15\% этих студентов характерен максимальный индекс против 50\% - 2 группа; для 50\% характерен средний индекс против 30\% - 2 группа; для 35\% характерен низкий индекс против 20\% - 2 группа.

Следовательно, средний уровень индекса жизненной удовлетворенности наиболее характерен для студентов 1 гуппы. На наш взгляд, для творческой личности более характерна повышенная эмоциональность, которая оказывает огромное влияние на самоощущение "здесь и сейчас», и определяет склонность к сомнениям и критическим оценкам окружающего мира.

Подводя итоги, следует отметить, что студенты, занимающиеся дополнительно творчеством, нацелены на получение диплома, а не на приобретение знаний и профессию. Тем не менее, у них преобладает положительный эмоциональный настрой и высокая оценка себя. Однако, в целом общий индекс жизненной удовлетворенности недостаточно высок, т.к. идет рассогласование в постановке и достижении целей. Безусловно, такие студенты требуют особого внимания в процессе не только профессионального обучения, но и их личностного самоопределения.

\section{Литература}

1. Большой психологический словарь / Под ред. Мещерякова Б.Г., Зинченко В.П. - М.: Прайм-Еврознак, 2013.

2. Головаха Е.И., Кроник А.А. К исследованию мотивации жизненного пути // Мотивация личности. - М.: ВЛАДОС, 2012.

3. Додонов Б.И. Эмоции как ценность. - М.: ЧеРо: Омега-Л МПСИ,2006.

4. Зимняя И.А. Педагогическая психология: учебник для студентов по пед. и психол. направ. и спец. - М.: Логос, 2013.

5. Очкина А.В. Концепция изменилась? По следам реформаторов от образования. // Левая политика. - 2007. - №1. - С. 56.

6. Шамионов Р.М. Субъективное благополучие личности: психологическая картина и фракторы. Саратов: Научная книга, 2008. 


\section{SPECIFICS OF SATISAFACTION WITH LIFE AND OF MOTIVATION AMONG STUDENTS ENGAGED IN CREATIVE WORK}

Akhryamkina T.A., (Samara Branch of State Autonomous Institution of Higher Education of the city of Moscow "Moscow City University", Samara, Russia)

The article dwells on the problems of professional and personal self-identification of young people and analyzes characteristic specifics of motivation towards learning and of satisfaction with life among students involved in a creative collective. The article summarizes the approaches towards the notion of "satisfaction with life" among psychologists representing various standpoints. Based on the research the role of creative work done by students is identified with respect to their future professional establishment.

Keywords: self-identification, motivation towards learning, satisfaction with life, creativity. 